\title{
A Comparison of Thermal Models for Temperature Profiles in Gas-Lift Wells
}

\author{
Langfeng Mu ${ }^{1}$, Qiushi Zhang ${ }^{2, *}, \mathrm{Qi} \mathrm{Li}^{3}$ and Fanhua Zeng ${ }^{2}$ \\ 1 Chinese Academy of Geological Sciences, No. 26 Baiwanzhuang Street, Beijing 100037, China; \\ jollyjessie@126.com \\ 2 Petroleum Systems Engineering, University of Regina, Regina, SK S4S 0A2, Canada; fanhua.zeng@uregina.ca \\ 3 Daqing Oilfield Exploration and Development Institute, Daqing 163712, China; happychenwei1983@163.com \\ * Correspondence: qzc089@uregina.ca; Tel.: +1-306-999-3778
}

Received: 26 January 2018; Accepted: 22 February 2018; Published: 26 February 2018

\begin{abstract}
Gas lift is a simple, reliable artificial lift method which is frequently used in offshore oil field developments. In order to enhance the efficiency of production by gas lift, it is vital to exactly predict the distribution of temperature-field for fluid within the wellbore. A new mechanistic model is developed for computing flowing fluid temperature profiles in both conduits simultaneously for a continuous-flow gas-lift operation. This model assumes steady heat transfer in the formation, as well as steady heat transfer in the conduits. A micro-units discrete from the wellbore, whose heat transfer process is analyzed and whose heat transfer equation is set up according to the law of conservation of energy. A simplified algebraic solution to our model is conducted to analyze the temperature profile. Sensitivity analysis was conducted with the new model. The results indicate that mass flow rate of oil and the tubing overall heat transfer coefficient are the main factors that influence the temperature distribution inside the tubing and that the mass flow rate of oil is the main factor affecting temperature distribution in the annulus. Finally, the new model was tested in three various wells and compared with other models. The results showed that the new model is more accurate and provides significant references for temperature prediction in gas lift well.
\end{abstract}

Keywords: temperature profile; gas lift; governing equation; wellbore profile

\section{Introduction}

As reservoir pressure declines, the production decreases and there is a need to use artificial lift methods to increase the production rate [1-3]. Gas lift is one of the industry's choices to develop low pressure fields. The gas, after being injected into the casing-tubing annulus at the wellhead, enters the production tubing via a gas lift valve situated in the gas lift mandrel [4,5]. Then the gas mixes with the produced fluids in the tubing, aerating the produced fluids and causing them to rise to the surface [6]. Gas-lift technology has evolved and matured over the years since the pioneering works of Poettmann-Carpenter [7] and Bertuzzi et al. [8] in the early 1950s. Through years of development, gas-lift technique has matured gradually.

Fluid temperature enters into a variety of petroleum production operations calculations, including well drilling and completions, production facility design, controlling solid deposition, and analyzing pressure transient test data [9]. In terms of gas-lift design, the thermally actuated safety valves have been used since the 1930s in many different applications. A thermally actuated safety valve would rely on a change in temperature between normal operation and an undesirable flow event [10]. In order to realize the productivity calculation during gas-lift and explore the oil-gas resource efficiently, it is vital to exactly predict distribution of temperature-field for fluid within the wellbore.

Many scholars have carried out different studies on rock heat-transfer within gas strata of wellbores over the last few decades. One of the earliest works on predicting temperature profiles 
in a flowing well was presented by Kirkpatrick [11] in the early 1950s. He presented a simple flowing-temperature-gradient chart that could be used to predict gas-lift valve temperatures at the injection depth. Ramey and Edwardson [12] presented a theoretical model to estimate fluid temperature as a function of well depth and production time. The model has been widely used in both geothermal and petroleum industries. However, the effects of kinetic energy and friction were ignored in the model, and therefore the model is only applicable to single-phase flow. There have been many modified temperature models (Shiu and Beggs [13]; Hasan et al. [14,15]) for two-phases flow in wellbore. Sagar et al. [16] extended Ramey's model to multiphase flow in wellbore by considering kinetic energy and Joule-Thompson expansion effects. Tartakovsky [17] present a Lagrangian particle model for multiphase multicomponent fluid flow, based on smoothed particle hydrodynamics. Farrokhpanah [18] further developed this method to study the heat transfer and phase change which was existed during $\mathrm{CO}_{2}$ migrating upwards along vertical leakage paths in wellbore [19]. Alves [20] presents a general and unified equation for flowing temperature prediction that is applicable for the entire range of inclination angles. The equation degenerates into Ramey's equations for ideal gas or incompressible liquid and into the Coulter and Bardon equation, with the appropriate assumptions. In addition, many scholars (Yanmin et al. [21]; Lindeberg [22]; Hamedi [23]; Kabir et al. [24]) further extended its application on the basis of previous studies. In 2013, Duan [25] predicted the temperature profile in a waxy oil-gas pipe flow and he considered the different parameters and used the heat balance in his model. Cheng [26] represented a model for distribution of thermal properties and oil saturations in steam injection wells. He involved the temperature logs in his studies. Han [27] studied the transient two phase fluid and heat transfer model with periodical electric heating. He analyzed the heat-flux conservation among different layers and presented the derivatives of temperature in location and time. The solution was obtained numerically to capture the temperature/pressure distribution profiles under transient conditions.

To design a gas-lift system from the viewpoints of both fluid flow and valve mechanics, an accurate knowledge of fluid temperature in both strings is very desirable. This paper presents a new model to describe the temperature distribution in annulus and tubing during the operation of gas lift. We also discuss the influence of relevant parameters. Moreover, this methodology is applied to some field cases to compare with other models.

\section{Methodology}

Temperature distribution in the wellbore is very important during the gas lift operation, which laid the foundations for the analysis and prediction of fluid flow in oil pipe, and the determination of position of the suction valve, etc. Numerical simulation calculation with all factors was difficult to achieve for the complex steam injection process in the wellbore.

Figure 1 depicts a small element of a borehole section with a tubing string at center. As shown, gas will be injected into the annulus and mixed with the fluid from the reservoir, and then flow to the surface through the tubing. There will be two heat transfers in this process, which are the one between fluid in the annulus and the formation and the one between fluid inside tubing and fluid in the annulus. Therefore, the following assumptions are made in model formulation. 


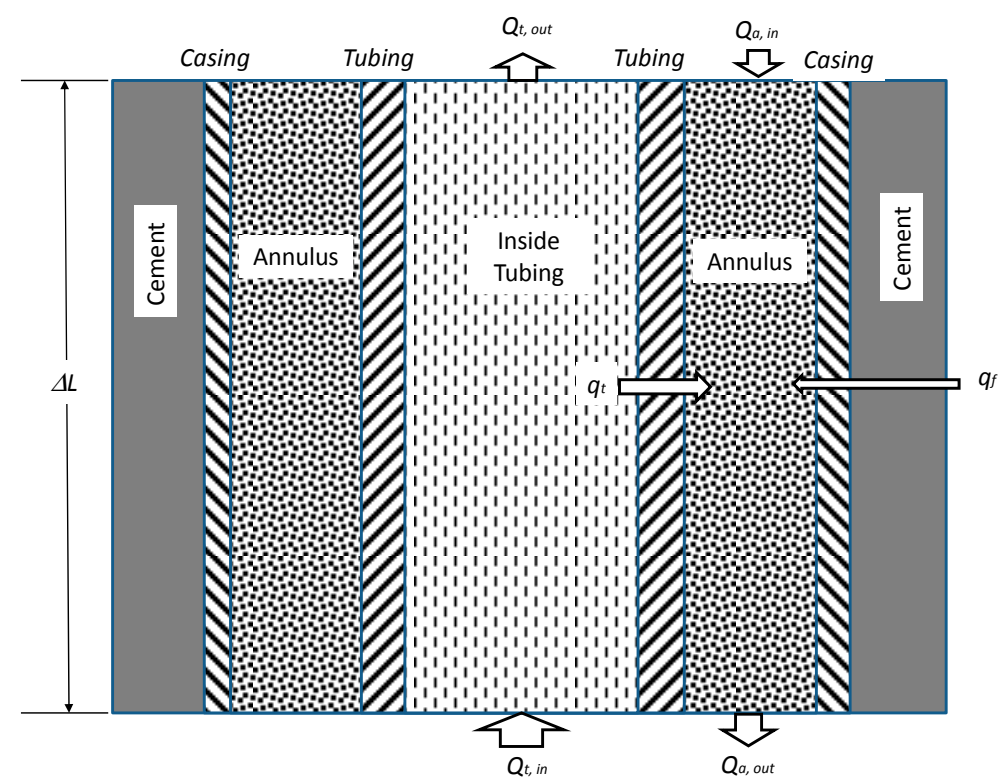

Figure 1. Sketch illustrating heat transfer in a wellbore section.

\subsection{Assumptions}

(1) The thermal conductivity of casing is assumed to be infinity.

(2) The geothermal gradient behind the annulus is not affected by borehole fluid.

(3) Heat capacity of the fluid is constant.

(4) Friction-induced heat is negligible.

\subsection{Governing Equation}

(1) Flow in the annulus

Consider the heat transfer in the annulus of length $L$ during a short time period of $\Delta t$. Heat energy balance is given by:

$$
Q_{a, \text { in }}+q_{f}+q_{t}-Q_{a, \text { out }}=Q_{a, \text { change }}
$$

where $Q_{a, \text { in }}$ is the heat energy brought into the annular element by the annular fluid due to convection; $q_{f}$ is the heat transfer from the formation rock to the annulus due to conduction; $q_{t}$ is the heat transfer from the tubing fluid to the annulus due to conduction; $Q_{a, \text { out }}$ is the heat energy carried away from the annular element by the annular fluid due to convection; $Q_{a, \text { change }}$ is the change of heat energy in the annular fluid in the element.

Substitute equations of above coefficients into Equation (1) and the governing equation for annulus temperature $T_{a}$ can be obtained (Appendix A):

$$
\frac{\partial T_{a}}{\partial L}+\alpha \frac{\partial T_{a}}{\partial t}+(\gamma-\beta) T_{a}-\gamma T_{t}+\beta G L+\beta T_{g 0}=0
$$

where

$$
\begin{aligned}
\alpha & =\frac{\pi \rho_{a}\left(d_{c}^{2}-D_{t}^{2}\right)}{4 m_{a}} \\
\beta & =\frac{2 \pi D_{c} K_{c}}{C_{a} m_{a}\left(D_{w}-D_{c}\right)} \\
\gamma & =\frac{2 \pi D_{t} K_{t}}{C_{a} m_{a}\left(D_{t}-d_{t}\right)}
\end{aligned}
$$


(2) Flow in the tubing

Consider the heat transfer in the tubing element of length $\Delta L$ during a time period of $\Delta t$. Heat balance is given by

$$
Q_{t, \text { in }}-q_{t}-Q_{t, \text { out }}=Q_{t, \text { change }}
$$

where $Q_{t, i n}$ is the heat energy brought into the tubing element by the tubing fluid due to convection; $q_{t}$ is the heat transfer from the tubing fluid to the annulus due to conduction; $Q_{t, o u t}$ is the heat energy carried away from the tubing element by the tubing fluid due to convection; $Q_{t, \text { change }}$ is the change of heat energy in the tubing fluid in the element.

Substituting the coefficient equations into Equation (6) the governing equation for tubing temperature $T_{t}$ can be obtained (Appendix A):

$$
\frac{\partial T_{t}}{\partial L}+a \frac{\partial T_{t}}{\partial t}-b T_{t}+b T_{a}=0
$$

where

$$
\begin{gathered}
a=-\frac{\pi \rho_{t} d_{t}^{2}}{4 m_{t}} \\
b=\frac{2 \pi D_{t} K_{t}}{C_{t} m_{t}\left(D_{t}-d_{t}\right)}
\end{gathered}
$$

\subsection{Boundary Conditions}

The boundary condition for solving Equation (2) is expressed as:

$$
T_{a}=T_{a 0} \text { at } L=L_{\max }
$$

The boundary condition for solving Equation (7) is expressed as:

$$
T_{t}=T_{\max } \text { at } L=L_{\max }
$$

where

$$
T_{\max }=\frac{C_{a} m_{a}\left(T_{a}-T_{J T}\right)+C_{o} m_{o} T_{o}}{C_{a} m_{a}+C_{o} m_{o}}
$$

where $T_{J T}$ is the gas temperature drop due to the Joule-Thomason cooling effect [28] which is assumed to be $0.16 T_{a}$ gas under sonic flow conditions across the gas injection valve, Equation (10) is expressed as:

$$
T_{\max }=\frac{0.84 C_{a} m_{a} T_{a}+C_{o} m_{o} T_{o}}{C_{a} m_{a}+C_{o} m_{o}}
$$

\subsection{Analytical Solution}

The details of solving the Equations (2) and (7) are presented in Appendix A. The resultant solutions are summarized as follows:

$$
\begin{gathered}
T_{a}=-\frac{F-E M_{2}}{M_{1}-M_{2}} \gamma e^{r_{1} L}-\frac{F-E M_{1}}{M_{2}-M_{1}} \gamma e^{r_{2} L}+\frac{\beta G b}{\gamma b-(\gamma-\beta) b} L \\
+\frac{\beta G b^{2}-\gamma \beta G b-(\gamma-\beta) \beta T_{g 0} b^{2}+\gamma \beta T_{g 0} b^{2}}{[\gamma b-(\gamma-\beta) b]^{2}} \\
T_{t}=\frac{F-E M_{2}}{M_{1}-M_{2}}\left[\beta-\gamma-r_{1}\right] e^{r_{1} L}+\frac{F-E M_{1}}{M_{2}-M_{1}}\left[\beta-\gamma-r_{2}\right] e^{r_{2} L}+\frac{\beta G b}{\gamma b-(\gamma-\beta) b} L \\
-\frac{\left[(\gamma-\beta) \beta G-\beta G b-\gamma \beta T_{g 0} b+(\gamma-\beta) \beta T_{g 0} b\right] b}{[\gamma b-(\gamma-\beta) b]^{2}}
\end{gathered}
$$




\section{Results and Discussion}

\subsection{Sensitivity Analysis}

There are plenty of factors that affect the temperature distribution of fluid within tubing and casing, and production tools and the production system change the nature of each factor. Moreover, there is no correlation with each other. Therefore, this paper makes a comparison on the basis of the first law of thermodynamics and reduced temperature for convenient sensitivity analysis and for creating formulas. A base value is set and the single factor is fluctuated above and below that basic value. Afterwards, the range for the temperature within the tubing, casing and the entire wellbore is calculated (according to basic value). In this way, the calculation results are comparable.

\subsubsection{Sensitivity Analysis Method}

After variation amplitude value is computed based on the aforementioned approach, the influence degree of each factor is then calculated according to Equation (14):

$$
k_{i}=a_{i} / \sum_{i=1}^{4} a_{i}
$$

where $k_{i}$ is the extent of influence and $a_{i}$ is the gradient of absolute value. The result shows which factor has the biggest impact on temperature within the wellbore under the same fluctuation range.

\subsubsection{Basic Parameters}

In order to determine the parameters that affect temperature distribution (namely, key controlling factors) and the extent of their influence, this paper makes parameter sensitive analysis for each production index, based on exploring internal energy of the fluid within the tubing and casing, and then confirms its controlling factors according to heat gradient (rate) with the variation of different parameters. The basis of the project of sensitivity analysis is presented in Table 1.

Table 1. Range of Sensitive Parameter Values.

\begin{tabular}{cccc}
\hline Coefficient & \multicolumn{3}{c}{ Value } \\
\cline { 2 - 4 } Well depth, $\mathrm{m}$ & $\mathbf{\text { low }}$ & (High) & (Average) \\
Casing radius, $\mathrm{m}$ & - & - & 4572 \\
Tubing radius, $\mathrm{m}$ & - & - & 0.11 \\
Mass flow rate of oil, $\mathrm{kg} / \mathrm{s}$ & - & - & 0.07 \\
Mass fraction of gas in oil & 0.74 & 15.88 & 8.31 \\
Specific heat of oil, $\mathrm{J} / \mathrm{kg} \cdot \mathrm{K})$ & 0.05 & 0.10 & 0.075 \\
Specific heat of gas, $\mathrm{J} / \mathrm{kg} \cdot \mathrm{K})$ & - & - & 1674.72 \\
Tubing overall heat transfer coefficient, $\mathrm{W} /\left(\mathrm{m}^{2} \cdot \mathrm{K}\right)$ & 28.39 & 113.57 & 70.98 \\
Annulus overall heat transfer coefficient, $\mathrm{W} /\left(\mathrm{m}^{2} \cdot \mathrm{K}\right)$ & 11.36 & 22.71 & 17.03 \\
Geothermal gradient, $\mathrm{K} / \mathrm{m}$ & - & - & 0.0427 \\
Bottomhole earth temperature, $\mathrm{K}$ & - & - & 394.26 \\
Surface earth temperature, $\mathrm{K}$ & - & - & 288.43 \\
Surface gas inlet temperature, $\mathrm{K}$ & - & - & 318.15 \\
\hline
\end{tabular}

Each average value (Table 1) within the range defined by coefficient intervals is selected as the basic contrasting evidence, and Figure 2 shows the temperature profile curve in the annulus, tubing and geothermal gradient. 


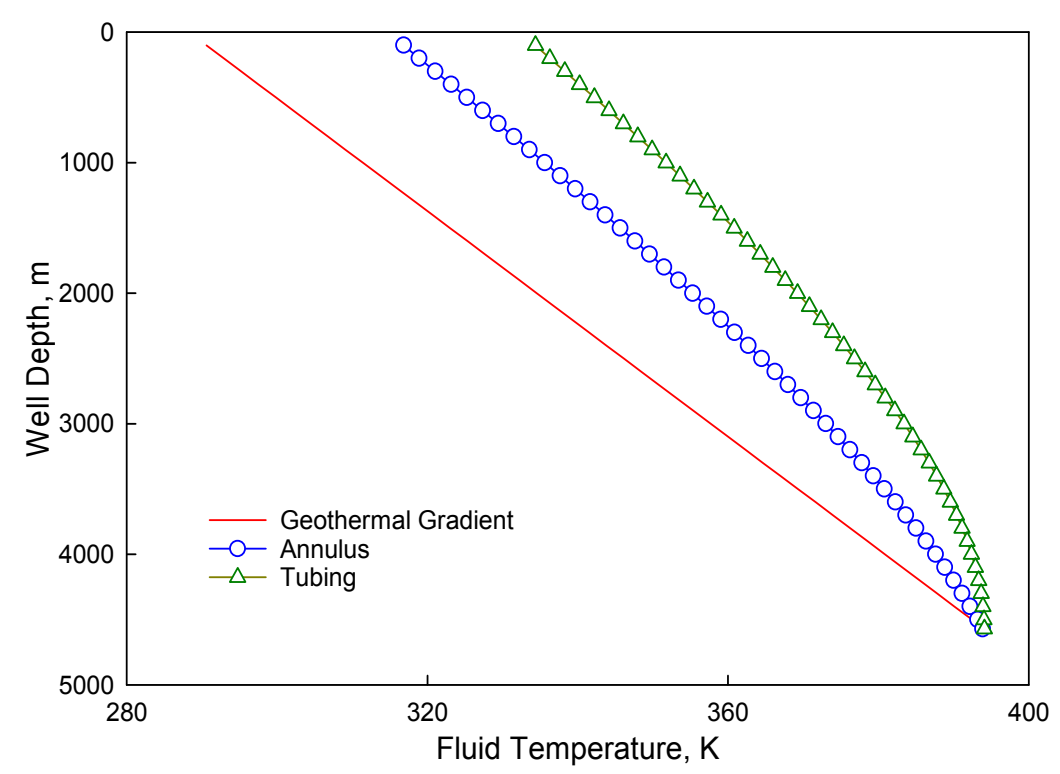

Figure 2. Baseline for sensitivity analysis.

Mass flow rate of oil, mass fraction of gas in oil, tubing overall heat transfer coefficient, annulus overall heat transfer coefficient are shifted $20 \%, 40 \%$ and $60 \%$ up or down, respectively; then the resulting temperature change is calculated (Table 2).

Table 2. Values of Sensitized Parameters.

\begin{tabular}{ccccc}
\hline $\begin{array}{c}\text { Variation of } \\
\text { Parameters }\end{array}$ & $\begin{array}{c}\text { Mass Flow } \\
\text { Rate of Oil }\end{array}$ & $\begin{array}{c}\text { Mass Fraction } \\
\text { of Gas in Oil }\end{array}$ & $\begin{array}{c}\text { Tubing Overall } \\
\text { Heat Transfer } \\
\text { Coefficient }\end{array}$ & $\begin{array}{c}\text { Annulus Overall } \\
\text { Heat Transfer } \\
\text { Coefficient }\end{array}$ \\
\hline$-60 \%$ & 3.76 & 0.060 & 45.43 & 13.63 \\
$-40 \%$ & 5.28 & 0.065 & 53.94 & 14.76 \\
$-20 \%$ & 6.79 & 0.070 & 62.46 & 15.90 \\
$20 \%$ & 9.82 & 0.080 & 79.49 & 18.17 \\
$40 \%$ & 11.33 & 0.085 & 88.02 & 19.31 \\
$60 \%$ & 12.85 & 0.090 & 96.53 & 20.44 \\
\hline
\end{tabular}

\subsubsection{Major Factors Affecting Temperature Distribution inside Tubing}

Figure 3 shows that along with the increase of mass flow rate of oil, temperature within the tubing is rises as well. This is because more heat in the formation fluid is carried out of the oil well with the increase of mass flow rate of oil and the duration of the external heat transfer for fluid within the tubing is shortened during flow, which wholly improves the temperature within the tubing, and such an increase becomes smaller and smaller.

Figure 4 and Table 3 suggests that when each variable decreases, the influence of each factor on temperature within the tubing is as follows (from great to small): the mass flow rate of oil, the tubing overall heat transfer coefficient, the annulus overall heat transfer coefficient, and the mass fraction of gas in oil. 


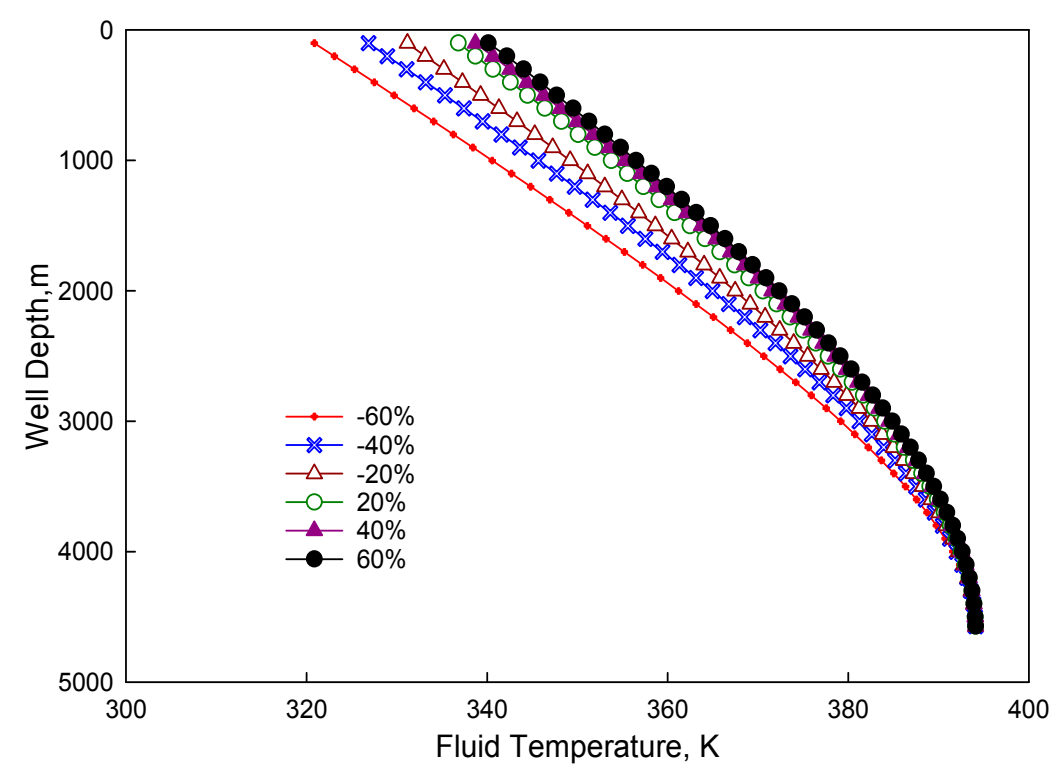

Figure 3. Effect of oil flow rate on the temperature distribution curve in the tubing.

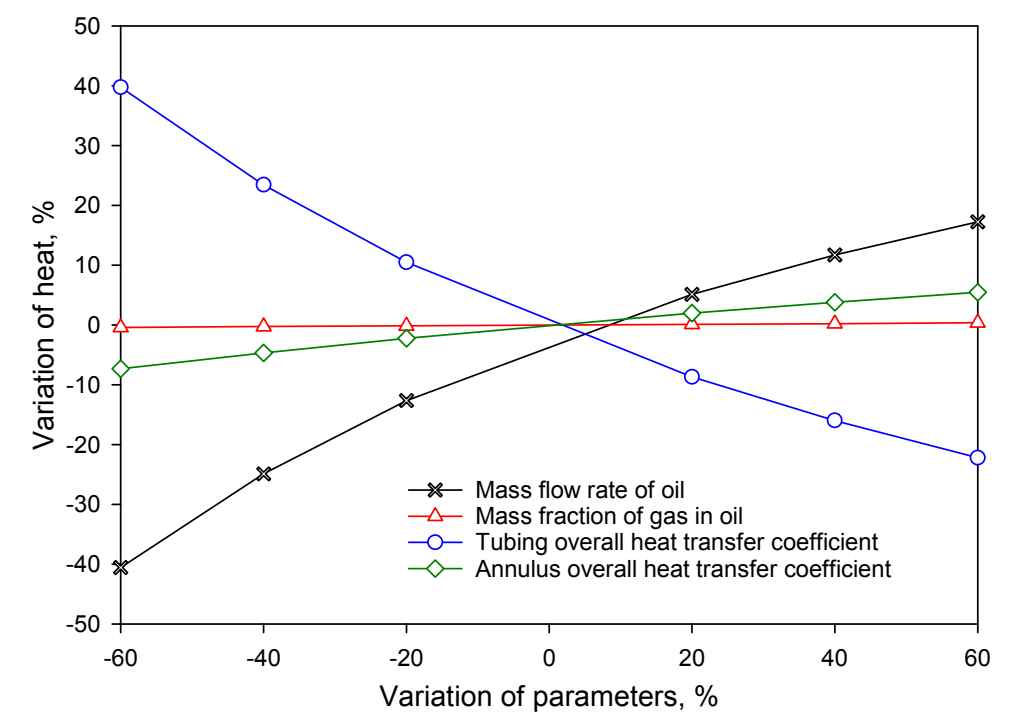

Figure 4. Sensitive analysis for temperature variation inside tubing.

Table 3. Influence of factors on temperature within the tubing.

\begin{tabular}{ccccc}
\hline $\begin{array}{c}\text { Parameter } \\
\text { Variations }\end{array}$ & $\begin{array}{c}\text { Mass Flow } \\
\text { Rate of Oil }\end{array}$ & $\begin{array}{c}\text { Mass Fraction } \\
\text { of Gas in Oil }\end{array}$ & $\begin{array}{c}\text { Tubing Overall } \\
\text { Heat Transfer } \\
\text { Coefficient }\end{array}$ & $\begin{array}{c}\text { Annulus Overall } \\
\text { Heat Transfer } \\
\text { Coefficient }\end{array}$ \\
\hline$-60 \%$ & $46.06 \%$ & $0.43 \%$ & $45.17 \%$ & $8.34 \%$ \\
$-40 \%$ & $46.79 \%$ & $0.48 \%$ & $44.03 \%$ & $8.71 \%$ \\
$-20 \%$ & $49.62 \%$ & $0.50 \%$ & $41.24 \%$ & $8.64 \%$ \\
$20 \%$ & $32.21 \%$ & $0.80 \%$ & $54.47 \%$ & $12.52 \%$ \\
$40 \%$ & $36.89 \%$ & $0.80 \%$ & $50.30 \%$ & $12.01 \%$ \\
$60 \%$ & $38.07 \%$ & $0.85 \%$ & $48.99 \%$ & $12.09 \%$ \\
\hline
\end{tabular}

\subsubsection{Major Factors Affecting Temperature Distribution in the Annulus}

Figure 5 shows that along with the increase of the mass flow rate of oil, the temperature within the casing also rises. This is because that the increase in temperature within the tubing enlarges the 
temperature differences between the both sides of tubing wall and heat transfer is thus enhanced, which leads to the rise in fluid temperature within casing.

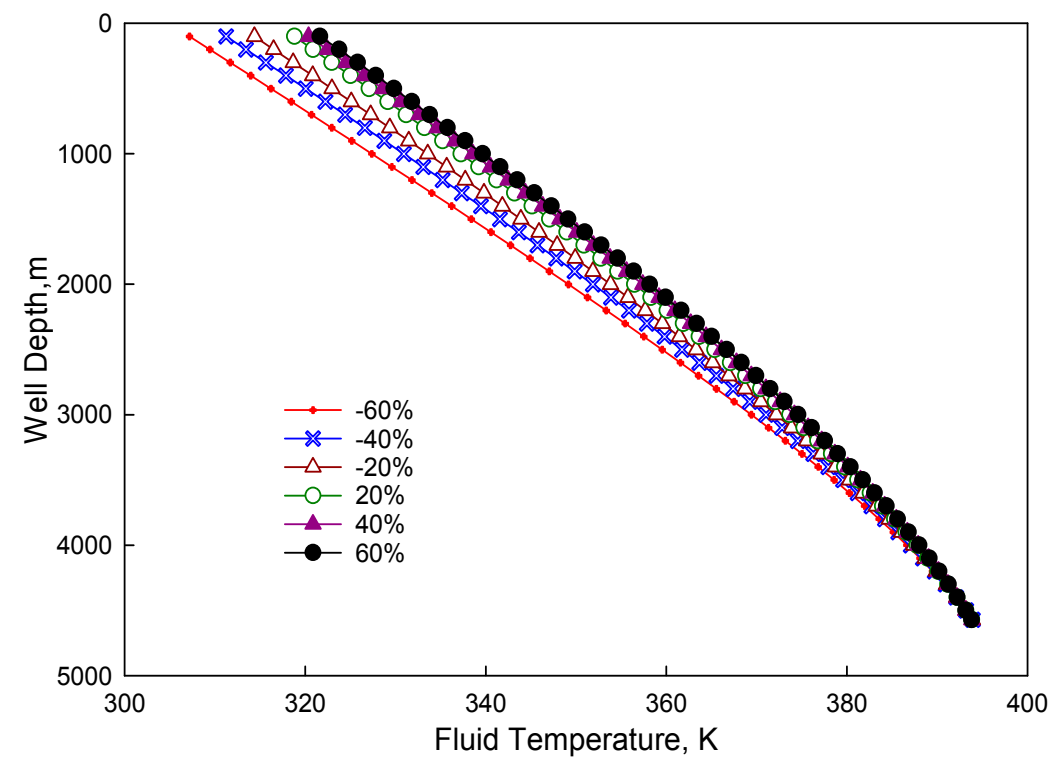

Figure 5. Effect of oil flow rate on the temperature distribution curve in the annulus.

Figure 6 and Table 4 suggests that the influence of each factor on temperature within tubing is as follows (from great to small): the mass flow rate of oil, the tubing overall heat transfer coefficient, the annulus overall heat transfer coefficient, the mass fraction of gas in oil.

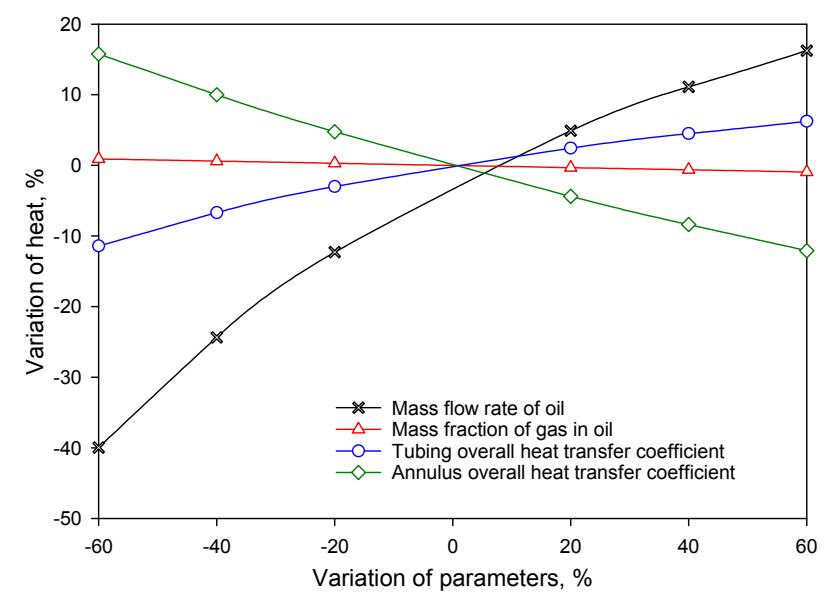

Figure 6. Sensitive analysis for temperature variation in the annulus.

Table 4. Influence of Factors on Temperature in the Annulus.

\begin{tabular}{ccccc}
\hline $\begin{array}{c}\text { Parameter } \\
\text { Variations }\end{array}$ & $\begin{array}{c}\text { Mass Flow } \\
\text { Rate of Oil }\end{array}$ & $\begin{array}{c}\text { Mass Fraction } \\
\text { of Gas in Oil }\end{array}$ & $\begin{array}{c}\text { Tubing Overall } \\
\text { Heat Transfer } \\
\text { Coefficient }\end{array}$ & $\begin{array}{c}\text { Annulus Overall } \\
\text { Heat Transfer } \\
\text { Coefficient }\end{array}$ \\
\hline$-60 \%$ & $58.70 \%$ & $1.36 \%$ & $16.77 \%$ & $23.18 \%$ \\
$-40 \%$ & $58.46 \%$ & $1.48 \%$ & $16.05 \%$ & $24.01 \%$ \\
$-20 \%$ & $60.33 \%$ & $1.52 \%$ & $14.68 \%$ & $23.47 \%$ \\
$20 \%$ & $40.80 \%$ & $2.57 \%$ & $20.37 \%$ & $36.27 \%$ \\
$40 \%$ & $45.19 \%$ & $2.51 \%$ & $18.29 \%$ & $34.01 \%$ \\
$60 \%$ & $45.80 \%$ & $2.61 \%$ & $17.58 \%$ & $34.01 \%$ \\
\hline
\end{tabular}




\subsection{Case Study}

Two thermal models which developed by Hasan [14] and Alves [20] are adopted to compare with our model.

\subsubsection{Case 1}

This field example is given to show the application of the new model. This case is taken from the published work of Hasan [14]. Table 5 presents all of the parameters used to compute the pressure and temperature traverses.

Table 5. Data for the Thompson Well.

\begin{tabular}{cc}
\hline Coefficient & Value \\
\hline Total well depth, $\mathrm{m}$ & 1529.79 \\
Depth of gas infection, $\mathrm{m}$ & 731.52 \\
Casing ID, $\mathrm{m}$ & 0.18 \\
Tubing OD, $\mathrm{m}$ & 0.073 \\
Oil + water flow rate, $\mathrm{m}^{3} / \mathrm{s}$ & 0.0038 \\
Mass fraction of gas in the tubing & 0.0681 \\
Gas $/$ liquid ratio, $\mathrm{m}^{3} / \mathrm{m}^{3}$ & 97.9 \\
Oil + water API gravity & 10.3 \\
Gas gravity (air $=1$ ) & 0.61 \\
Specific heat of liquid, $\mathrm{J} /(\mathrm{kg} \cdot \mathrm{K})$ & 4186.8 \\
Specific heat of gas, $\mathrm{J} /(\mathrm{kg} \cdot \mathrm{K})$ & 1046.7 \\
Tubing overall heat transfer coefficient, $\mathrm{W} /\left(\mathrm{m}^{2} \cdot \mathrm{K}\right)$ & 56.78 (Hasan and Alves), 39.75 (New model) \\
Annulus overall heat transfer coefficient, $\mathrm{W} /\left(\mathrm{m}^{2} \cdot \mathrm{K}\right)$ & 22.71 \\
Earth thermal conductivity, $\mathrm{W} /(\mathrm{m} \cdot \mathrm{K})$ & 2.25 \\
Geothermal gradient, $\mathrm{K} / \mathrm{m}$ & 0.045 \\
Bottomhole earth temperature, $\mathrm{K}$ & 338.15 \\
Surface earh temperature, $\mathrm{K}$ & 299.82 \\
Surface gas inlet temperature, $\mathrm{K}$ & 310.93 \\
\hline
\end{tabular}

In this well, large discontinuity in the in-situ gas volume-fraction occurs at $2500 \mathrm{ft}$ where the lift gas is introduced through the annulus. The temperature profile below the injection point is computed by using a simplified model from our model. The assumptions of the simplified model are that a single phase fluid flows in the tubing and the heat transfer in annulus is neglected.

The corresponding tubing temperature profiles, both measured and computed, are shown in Figure 7. A good agreement is obtained between this model and measurement for temperature profiles.

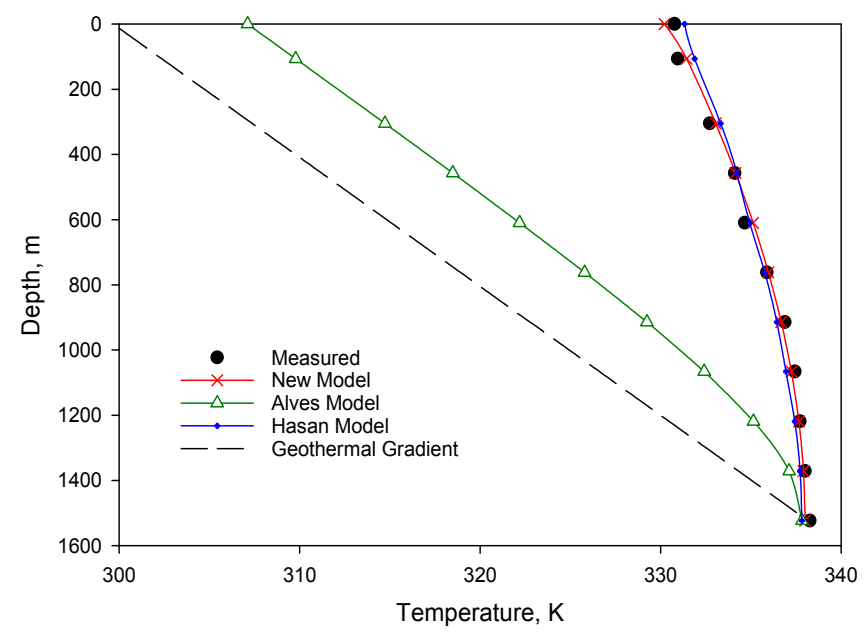

Figure 7. Comparison of data for the Thompson Well. 
However, the same was not true for the Alves Model. This is because that the Alves Model is derived for simulating multi-phases flowing in tubing and do not consider the effect made by heat transfer in annulus.

\subsubsection{Case 2}

The data for the O'Connor Well also comes from the published work of Hasan [14]. All the parameters used to compute the pressure and temperature profiles are presented in Table 6 . Because the geothermal gradient was not reported, we obtained a match by adjusting it.

Table 6. Data for the O'Connor Well.

\begin{tabular}{cc}
\hline Coefficient & Value \\
\hline Total well depth, $\mathrm{m}$ & 1517.5992 \\
Depth of gas infection, $\mathrm{m}$ & 673.303 \\
Casing ID, $\mathrm{m}$ & 0.127 \\
Tubing OD, $\mathrm{m}$ & 0.0635 \\
Oil + water flow rate, $\mathrm{m}^{3} / \mathrm{s}$ & 0.00674 \\
Mass fraction of gas in the tubing & 0.0225 \\
Gas /liquid ratio, $\mathrm{m}^{3} / \mathrm{m}^{3}$ & 28.124 \\
Oil + water API gravity & 26 \\
Gas gravity (air $=1$ ) & 0.60 \\
Specific heat of liquid, $\mathrm{J} /(\mathrm{kg} \cdot \mathrm{K})$ & 4186.8 \\
Specific heat of gas, $\mathrm{J} /(\mathrm{kg} \cdot \mathrm{K})$ & 1046.7 \\
Tubing overall heat transfer coefficient, $\mathrm{W} /\left(\mathrm{m}^{2} \cdot \mathrm{K}\right)$ & 56.78 (Hasan and Alves), 45.43 (New model) \\
Annulus overall heat transfer coefficient, $\mathrm{W} /\left(\mathrm{m}^{2} \cdot \mathrm{K}\right)$ & 5.68 (Hasan and Alves), 9.65 (New model) \\
Earth thermal conductivity, $\mathrm{W} /(\mathrm{m} \cdot \mathrm{K})$ & 2.25 \\
Geothermal gradient, $\mathrm{K} / \mathrm{m}$ & 0.0522 \\
Bottomhole earth temperature, $\mathrm{K}$ & 344.8 \\
Surface earh temperature, $\mathrm{K}$ & 300.93 \\
Surface gas inlet temperature, $\mathrm{K}$ & 310.93 \\
\hline
\end{tabular}

For the $\mathrm{O}^{\prime}$ Connor Well, Figure 8 shows that a good agreement in temperature occurs at shallower depths where two phases flow is prevalent but to a lesser degree near the point of gas injection. Just as mentioned in the literature, two possible reasons exist for this mismatch [14].

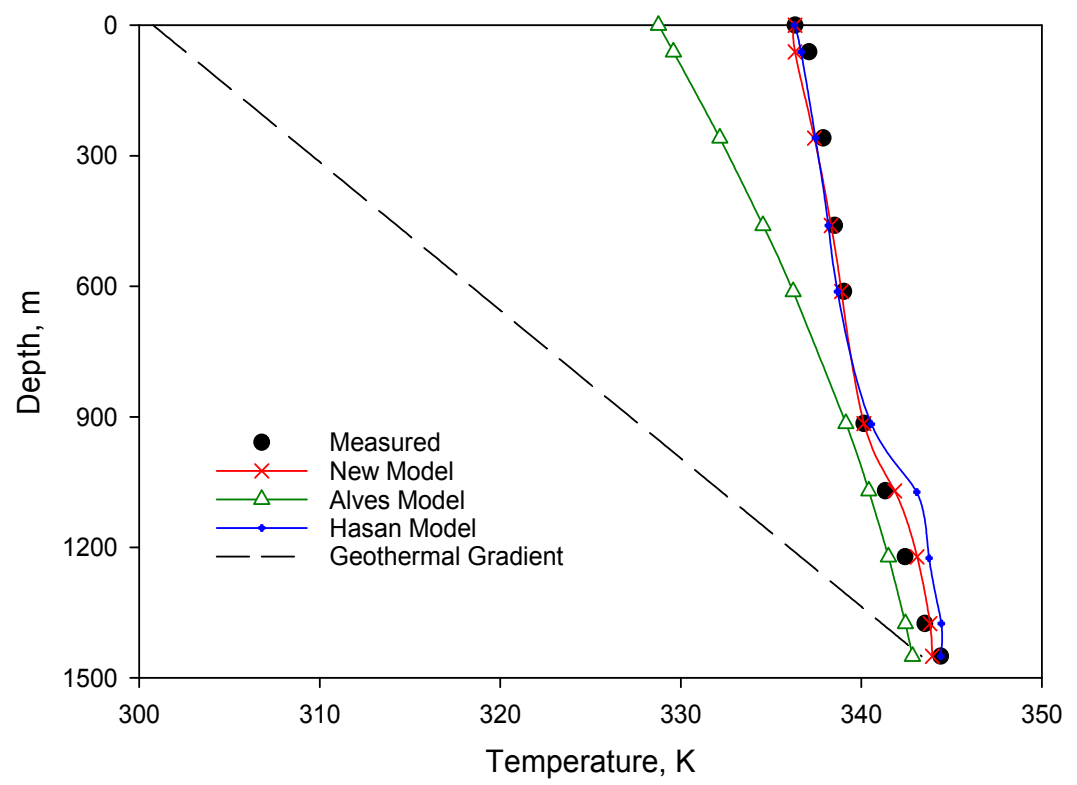

Figure 8. Comparison of data for the $\mathrm{O}^{\prime}$ Connor Well. 
Either the geothermal gradient is substantially different below the point of gas injection, or short-duration station stops did not allow for the thermometer to equilibrate with the fluid temperature. There is significant error near injection point.

\subsubsection{Case 3}

Luo Wei [29] computed temperature distribution of gas-lift production in a certain oil field. This oil-field was mined by adopting the gas-lift annulus, and in order to solve the problem of wax growth at $2624.67 \mathrm{ft}$ above the oil well, the experiment was performed in which experiment the temperature of produced liquid within the wellbore was increased by trying to add the injection temperature. Afterwards, research analysis is conducted by taking data in this oil field as a case. Table 7 lists the basic parameters of the well and measured data.

Table 7. Data for the Luo Wei Well.

\begin{tabular}{cc}
\hline Coefficient & Value \\
\hline Depth of oil layer, $\mathrm{m}$ & 2691.01 \\
Temperature in the mid-layer, $\mathrm{K}$ & 399.07 \\
Relative density of crude oil & 0.8375 \\
Relative density of output gas & 0.7103 \\
Proportion of injected gas & 0.65 \\
Tubing size, $\mathrm{m}$ & 0.073 \\
Casing size, $\mathrm{m}$ & 0.178 \\
Geothermal gradient, $\mathrm{K} / \mathrm{m}$ & 0.068 \\
Injected point, $\mathrm{m}$ & 2511.13 \\
Gas injection volume, $\mathrm{m}^{3} / \mathrm{s}$ & 0.092 \\
Liquid production volume, $\mathrm{m}^{3} / \mathrm{s}$ & 0.0001414 \\
Oil production, $\mathrm{m}^{3} / \mathrm{s}$ & 0.000113 \\
Gas production, $\mathrm{m}^{3} / \mathrm{s}$ & 0.139 \\
Moisture content $/ \%$ ) & 19.9 \\
Temperature of injected gas, $\mathrm{K}$ & 313.15 \\
\hline
\end{tabular}

For the Luo Wei well, Figure 9 shows that good agreement in temperature profile at shallower depths exists, but to a lesser degree around the point of gas injection. The measured temperature profile is only from the surface to the injection point.

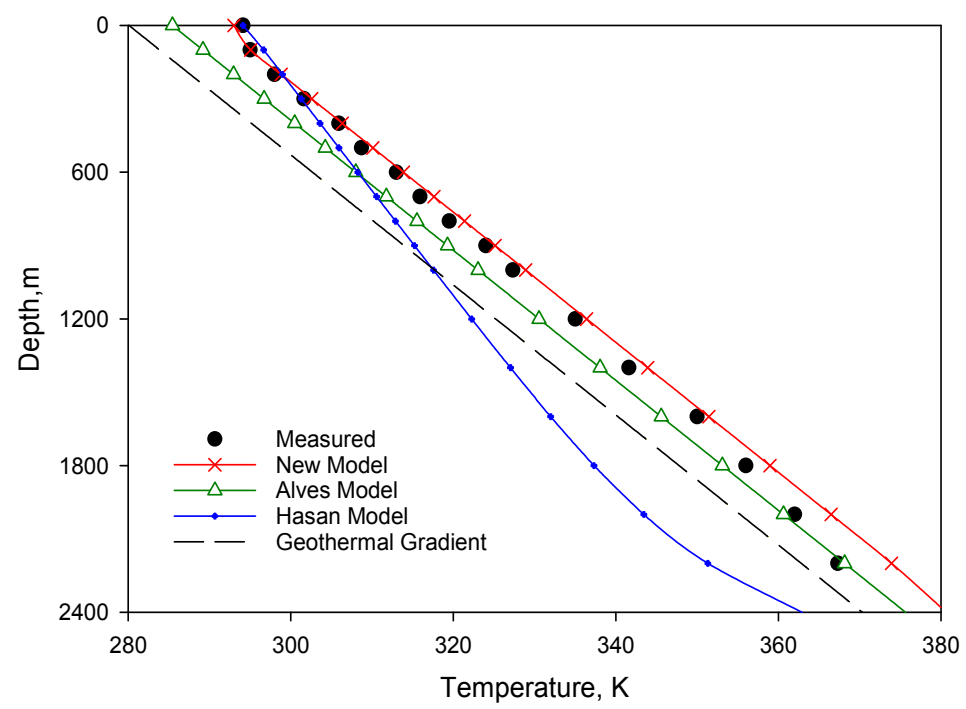

Figure 9. Comparison of data for the Luo Wei Well. 
The possible reason for this mismatch is that the geothermal gradient is substantially different owing to the different formation properties below the point of gas injection and this difference may have an effect on the temperature distribution around the injection point.

\section{Conclusions}

The following conclusions are drawn:

(1) A new mechanistic model is developed for computing flowing fluid temperature profiles in both conduits simultaneously for a continuous-flow gas-lift operation. The model assumes steady heat transfer in the formation, as well as steady heat transfer in the conduits. This work also presents a simplified algebraic solution to the analytic model, affording easy implementation in any existing program. An accurate fluid temperature computation should allow improved gas-lift design.

(2) Comparisons of the Hasan model, Alves model and the new model with data from three actual well show that the temperature profile given by the new model has a better accuracy than that of other models.

(3) A sensitivity analysis is conducted with the new model. The results indicate that:

(a) The mass flow rate of oil and the tubing overall heat transfer coefficient are the main factors that influence the temperature distribution inside the tubing;

(b) The mass flow rate of oil is the main factor affecting temperature distribution in the annulus. The annulus overall heat transfer coefficient of the annulus and overall heat transfer coefficient of the tubing are the next factors.

Author Contributions: Langfeng $\mathrm{Mu}$ and Qiushi Zhang conceived and designed the research contents and simulations; Qi Li analyzed the data; Langfeng Mu performed the calculation and wrote the paper; Fanhua Zeng and Qiushi Zhang checked the paper.

Conflicts of Interest: The authors declare no conflict of interest.

\section{Nomenclature}

$C_{a} \quad$ the heat capacity of annular fluid

$C_{0}$ the heat capacity of the produced fluid from the oil reservoir

$C_{t} \quad$ the heat capacity of the tubing fluid

$d_{t} \quad$ the inner diameter of the tubing

$D_{c} \quad$ the outer diameter of casing

$D_{t} \quad$ the outer diameter of tubing

$D_{w} \quad$ the diameter of the wellbore (to sandface)

$K_{t} \quad$ the thermal conductivity of tubing

$q_{f} \quad$ the heat transfer from the formation rock to the annulus due to conduction

$q_{t} \quad$ heat transfer from the tubing fluid to the annulus due to conduction

$Q_{a, i n} \quad$ The heat energy brought into the annular element by the annular fluid due to convection

$Q_{a, \text { out }} \quad$ the heat energy carried away from the annular element by the annular fluid due to convection

$Q_{a, \text { change }}$ the change of heat energy in the annular fluid in the element

$Q_{t, \text { in }} \quad$ the heat energy brought into the tubing element by the tubing fluid due to convection

$Q_{t, \text { out }} \quad$ the heat energy carried away from the tubing element by the tubing fluid due to convection

$Q_{t, \text { change }} \quad$ the change of heat energy in the tubing fluid in the element

$r \quad$ the radial distant

$T_{a 0} \quad$ surface temperature, $\mathrm{k}$

$T_{a, L} \quad$ the temperature of annular fluid at location $L$

$T_{a, L+\Delta L} \quad$ the temperature of annular fluid at location $L+\Delta L$ 
$T_{c} \quad$ the temperature in the cement sheath in the radial direction

$T_{g} \quad$ the geo-temperature at the depth $L$

$T_{J T} \quad$ the gas temperature drop due to the Joule-Thomason cooling effect

$T_{t} \quad$ the temperature of the tubing fluid at the depth $L$

$T_{t, L+\Delta L} \quad$ the temperature of the tubing fluid at location $L+\Delta L$

$T_{t b} \quad$ the temperature in the tubing in the radial direction

$m_{a} \quad$ the mass flow rate of annular fluid

$m_{0} \quad$ The mass flow rate of the produced fluid from the oil reservoir

$m_{t} \quad$ the mass flow rate of the tubing fluid

\section{Appendix}

(1) Flow in the annulus

Consider the heat transfer in the annulus of length $L$ during a short time period of $\Delta t$. Heat energy balance is given by:

$$
Q_{a, \text { in }}+q_{f}+q_{t}-Q_{a, \text { out }}=Q_{a, \text { change }}
$$

The $Q_{a, i n}$ term can be expressed as:

$$
Q_{a, i n}=C_{a} m_{a} T_{a, L} \Delta t
$$

The $q_{f}$ term is formulated as:

$$
q_{f}=\pi D_{c} K_{c} \Delta L\left(\frac{\partial T_{\mathcal{c}}}{\partial r}\right) \Delta t
$$

The $q_{t}$ term is expressed as:

$$
q_{t}=\pi D_{t} K_{t} \Delta L\left(-\frac{\partial T_{t b}}{\partial r}\right) \Delta t
$$

The $Q_{a, o u t}$ term is formulated as:

$$
Q_{a, o u t}=C_{a} m_{a} T_{a, L+\Delta t} \Delta t
$$

The $Q_{a, \text { change }}$ term is expressed as:

$$
Q_{a, \text { change }}=C_{a} \rho_{a} A_{a} \Delta L \Delta T_{a}
$$

Substituting Equations (A2) through (A6) into Equation (A1) gives

$$
C_{a} m_{a} T_{a, L} \Delta t+\pi D_{c} K_{c} \Delta L\left(\frac{\partial T_{c}}{\partial r}\right) \Delta t+\pi D_{t} K_{t} \Delta L\left(-\frac{\partial T_{t b}}{\partial r}\right) \Delta t-C_{a} m_{a} T_{a, L+\Delta L} \Delta t=C_{a} \rho_{a} A_{a} \Delta L \Delta T_{a}
$$

which is rearranged to get:

$$
C_{a} m_{a} \Delta t\left(T_{a, L}-T_{a, L+\Delta L}\right)+\pi D_{c} K_{c} \Delta L\left(\frac{\partial T_{c}}{\partial r}\right) \Delta t+\pi D_{t} K_{t} \Delta L\left(-\frac{\partial T_{t b}}{\partial r}\right) \Delta t=C_{a} \rho_{a} A_{a} \Delta L \Delta T_{a}
$$

where the temperature gradient terms can be formulated as:

$$
\frac{\partial T_{c}}{\partial r}=\frac{T_{g}-T_{a}}{\frac{\left(D_{w}-D_{c}\right)}{2}}
$$

and:

$$
\frac{\partial T_{t b}}{\partial r}=\frac{T_{a}-T_{t}}{\frac{\left(D_{t}-d_{t}\right)}{2}}
$$

Substituting Equations (A9) and (A10) into Equation (A8) gives:

$$
C_{a} m_{a} \Delta t\left(T_{a, L}-T_{a, L+\Delta L}\right)+2 \pi D_{c} K_{c} \Delta L \frac{\left(T_{g}-T_{a}\right)}{\left(D_{w}-D_{c}\right)} \Delta t-2 \pi D_{t} K_{t} \Delta L \frac{\left(T_{a}-T_{t}\right)}{\left(D_{t}-d_{t}\right)} \Delta t=C_{a} \rho_{a} A_{a} \Delta L \Delta T_{a}
$$

Dividing all the terms of this equation by $\Delta L \Delta t$ yields:

$$
C_{a} m_{a} \frac{\left(T_{a, L}-T_{a, L+\Delta L}\right)}{\Delta L}+2 \pi D_{c} K_{c} \frac{\left(T_{g}-T_{a}\right)}{\left(D_{w}-D_{c}\right)}-2 \pi D_{t} K_{t} \frac{\left(T_{a}-T_{t}\right)}{\left(D_{t}-d_{t}\right)}=\frac{C_{a} \rho_{a} A_{a} \Delta T_{a}}{\Delta t}
$$


For infinitesimal of $\Delta L$ and $\Delta t$, this equation becomes:

$$
-C_{a} m_{a} \frac{\partial T_{a}}{\partial L}+2 \pi D_{c} K_{c} \frac{\left(T_{g}-T_{a}\right)}{\left(D_{w}-D_{c}\right)}-2 \pi D_{t} K_{t} \frac{\left(T_{a}-T_{t}\right)}{\left(D_{t}-d_{t}\right)}=C_{a} \rho_{a} A_{a} \frac{\partial T_{a}}{\partial t}
$$

Substituting $A_{a}=\frac{\pi\left(d_{c}^{2}-D_{t}^{2}\right)}{4}$ for Equation (A13) and rearranging the latter yields:

$$
\frac{\partial T_{a}}{\partial L}+\alpha \frac{\partial T_{a}}{\partial t}+\beta\left(T_{g}-T_{a}\right)+\gamma\left(T_{a}-T_{t}\right)=0
$$

where

$$
\begin{gathered}
\alpha=\frac{\pi \rho_{a}\left(d_{c}^{2}-D_{t}^{2}\right)}{4 m_{a}} \\
\beta=\frac{2 \pi D_{c} K_{c}}{C_{a} m_{a}\left(D_{w}-D_{c}\right)} \\
\gamma=\frac{2 \pi D_{t} K_{t}}{C_{a} m_{a}\left(D_{t}-d_{t}\right)}
\end{gathered}
$$

Substituting $T_{g}=T_{g 0}+G L$ for Equation (A14) yields the governing equation for annular temperature $T_{a}$ :

$$
\frac{\partial T_{a}}{\partial L}+\alpha \frac{\partial T_{a}}{\partial t}+(\gamma-\beta) T_{a}-\gamma T_{t}+\beta G L+\beta T_{g 0}=0
$$

(2) Flow in the tubing

Consider the heat transfer in the tubing element of length $\Delta L$ during a time period of $\Delta t$. Heat balance is given by

$$
Q_{t, \text { in }}-q_{t}-Q_{t, \text { out }}=Q_{t, \text { change }}
$$

The $Q_{t, \text { in }}$ term can be expressed as

$$
Q_{t, i n}=C_{t} m_{t} T_{t, L+\Delta L} \Delta t
$$

The $Q_{t, \text { out }}$ term is formulated as

$$
Q_{t, o u t}=C_{t} m_{t} T_{t, L} \Delta t
$$

The $Q_{t, \text { change }}$ term is expressed as

$$
Q_{t, \text { change }}=C_{t} \rho_{t} A_{t} \Delta L \Delta T_{t}
$$

Substituting Equation (A4) and Equation (A20) through (A22) for Equation (A19) gives

$$
C_{t} m_{t} T_{t, L+\Delta L} \Delta t-\pi D_{t} K_{t} \Delta L\left(-\frac{\partial T_{t b}}{\partial r}\right) \Delta t-C_{t} m_{t} T_{t, L} \Delta t=C_{t} \rho_{t} A_{t} \Delta L \Delta T_{t}
$$

which is rearranged to yield:

$$
C_{t} m_{t} \Delta t\left(T_{t, L+\Delta L}-T_{t, L}\right)-\pi D_{t} K_{t} \Delta L\left(-\frac{\partial T_{t b}}{\partial r}\right) \Delta t=C_{t} \rho_{t} A_{t} \Delta L \Delta T_{t}
$$

where the temperature gradient terms can be formulated as:

$$
\frac{\partial T_{t b}}{\partial r}=\frac{T_{a}-T_{t}}{\frac{\left(D_{t}-d_{t}\right)}{2}}
$$

Substituting Equation (A25) for Equation (A24) gives:

$$
C_{t} m_{t} \Delta t\left(T_{t, L+\Delta L}-T_{t, L}\right)-\pi D_{t} K_{t} \Delta L\left(-\frac{T_{a}-T_{t}}{\frac{\left(D_{t}-d_{t}\right)}{2}}\right) \Delta t=C_{t} \rho_{t} A_{t} \Delta L \Delta T_{t}
$$

Dividing all the terms of this equation by $\Delta L \Delta t$ yields:

$$
C_{t} m_{t} \frac{\left(T_{t, L+\Delta L}-T_{t, L}\right)}{\Delta L}+2 \pi D_{t} K_{t} \frac{\left(T_{a}-T_{t}\right)}{\left(D_{t}-d_{t}\right)}=C_{t} \rho_{t} A_{t} \frac{\Delta T_{t}}{\Delta t}
$$


For infinitesimal $\Delta L$ and $\Delta t$, this equation becomes:

$$
C_{t} m_{t} \frac{\partial T_{t}}{\partial L}+2 \pi D_{t} K_{t} \frac{\left(T_{a}-T_{t}\right)}{\left(D_{t}-d_{t}\right)}=C_{t} \rho_{t} A_{t} \frac{\Delta T_{t}}{\Delta t}
$$

Substituting $A_{t}=\frac{\pi d_{t}^{2}}{4}$ for Equation (A28) and rearranging the later gives the governing equation for tubing temperature $T_{t}$ :

$$
\frac{\partial T_{t}}{\partial L}+a \frac{\partial T_{t}}{\partial t}-b T_{t}+b T_{a}=0
$$

where

$$
\begin{gathered}
a=-\frac{\pi \rho_{t} d_{t}^{2}}{4 m_{t}} \\
b=\frac{2 \pi D_{t} K_{t}}{C_{t} m_{t}\left(D_{t}-d_{t}\right)}
\end{gathered}
$$

Boundary conditions:

The boundary condition for solving Equation (A18) is expressed as:

$$
T_{a}=T_{a 0} \text { at } L=0
$$

The boundary condition for solving Equation (A29) is expressed as:

$$
T_{t}=T_{\max } \text { at } L=L_{\max }
$$

where

$$
T_{\max }=\frac{C_{a} m_{a}\left(T_{a}-T_{J T}\right)+C_{o} m_{o} T_{o}}{C_{a} m_{a}+C_{o} m_{o}}
$$

Under sonic flow conditions, Equation (A32) is expressed as:

$$
T_{\max }=\frac{0.84 C_{a} m_{a} T_{a}+C_{o} m_{o} T_{o}}{C_{a} m_{a}+C_{o} m_{o}}
$$

(3) Analytical Solution

Equation (A18):

$$
\frac{\partial T_{a}}{\partial L}+\alpha \frac{\partial T_{a}}{\partial t}+(\gamma-\beta) T_{a}-\gamma T_{t}+\beta G L+\beta T_{g 0}=0
$$

Equal to:

$$
\frac{\partial T_{a}}{\partial L}+(\gamma-\beta) T_{a}-\gamma T_{t}+\beta G L+\beta T_{g 0}=0
$$

Equation (A29):

$$
\frac{\partial T_{t}}{\partial L}+a \frac{\partial T_{t}}{\partial t}-b T_{t}+b T_{a}=0
$$

Equal to:

$$
\frac{\partial T_{t}}{\partial L}-b T_{t}+b T_{a}=0
$$

Solutions to these equations are given in Appendix A. The resultant solutions are summarized as follows. The temperature in the annulus is expressed as follows:

$$
\begin{gathered}
T_{a}=-C_{1} \gamma e^{r_{1} L}-C_{2} \gamma e^{r_{2} L}+\frac{\beta G b}{\gamma b-(\gamma-\beta) b} L \\
+\frac{\beta G b^{2}-\gamma \beta G b-(\gamma-\beta) \beta T_{g 0} b^{2}+\gamma \beta T_{g 0} b^{2}}{[\gamma b-(\gamma-\beta) b]^{2}} \\
T_{a}=-C_{1} \gamma e^{r_{1} L}-C_{2} \gamma e^{r_{2} L}+G L+\frac{G b-\gamma G+\beta T_{g 0} b}{\beta b}
\end{gathered}
$$


The temperature inside the tubing is expressed as follows:

$$
\begin{aligned}
& T_{t}= C_{1}\left[\beta-\gamma-r_{1}\right] e^{r_{1} L}+C_{2}\left[\beta-\gamma-r_{2}\right] e^{r_{2} L}-\frac{\beta G b}{-\gamma b+(\gamma-\beta) b} L \\
&-\frac{\left[(\gamma-\beta) \beta G-\beta G b-\gamma \beta T_{g 0} b+(\gamma-\beta) \beta T_{g 0} b\right] b}{[\gamma b-(\gamma-\beta) b]^{2}} \\
& T_{t}=C_{1}\left[\beta-\gamma-r_{1}\right] e^{r_{1} L}+C_{2}\left[\beta-\gamma-r_{2}\right] e^{r_{2} L}+G L-\frac{(\gamma-\beta) G-G b-\beta T_{g 0} b}{\beta b}
\end{aligned}
$$

$C_{1}, C_{2}$ which in the Equations (A36) and (A37) are undetermined coefficients (calculated by boundary conditions), where:

$$
\begin{gathered}
r_{1}=\frac{-a-h+\sqrt{(a-h)^{2}+4 b f}}{2}=\frac{\beta-\gamma+b+\sqrt{(\gamma-\beta+b)^{2}-4 \gamma b}}{2} \\
r_{2}=\frac{-a-h-\sqrt{(a-h)^{2}+4 b f}}{2}=\frac{\beta-\gamma+b-\sqrt{(\gamma-\beta+b)^{2}-4 \gamma b}}{2} \\
\alpha=\frac{\pi \rho_{a}\left(d_{c}^{2}-D_{t}^{2}\right)}{4 m_{a}} \\
\beta=\frac{2 \pi D_{c} K_{c}}{C_{a} m_{a}\left(D_{w}-D_{c}\right)} \\
\gamma=\frac{2 \pi D_{t} K_{t}}{C_{a} m_{a}\left(D_{t}-d_{t}\right)} \\
a=-\frac{\pi \rho_{t} d_{t}^{2}}{4 m_{t}} \\
b=\frac{2 \pi D_{t} K_{t}}{C_{t} m_{t}\left(D_{t}-d_{t}\right)}
\end{gathered}
$$

and then apply the boundary conditions:

$$
T_{a}=T_{a 0} \text { at } L=0
$$

According to (A36), this yields can get the following:

$$
T_{a 0}=-C_{1} \gamma-C_{2} \gamma+\frac{G b-\gamma G+\beta T_{g 0} b}{\beta b}
$$

Apply the boundary condition:

$$
T_{t}=T_{\max } \text { at } L=L_{\max }
$$

According to (A37), this yields can get the following:

$$
T_{\max }=C_{1}\left[\beta-\gamma-r_{1}\right] e^{r_{1} L_{\max }}+C_{2}\left[\beta-\gamma-r_{2}\right] e^{r_{2} L_{\max }}+G L_{\max }-\frac{(\gamma-\beta) G-G b-\beta T_{g 0} b}{\beta b}
$$

where $T_{\max }$ is:

$$
T_{\max }=\frac{C_{a} m_{a}\left(T_{L_{\max }}-T_{T T}\right)+C_{o} m_{o} T_{o}}{C_{a} m_{a}+C_{o} m_{o}}
$$

The Equation (A45) can be shown as follows:

$$
C_{1}+C_{2}=\frac{G b-\gamma G+\beta T_{g 0} b}{\gamma \beta b}-\frac{1}{\gamma} T_{a 0}=E
$$

The Equation (A46) can be shown as:

$$
\begin{gathered}
C_{1}\left[\beta-\gamma-r_{1}\right] e^{r_{1} L_{\max }}+C_{2}\left[\beta-\gamma-r_{2}\right] e^{r_{2} L_{\max }}=T_{\max }-G L_{\max }+\frac{\left[(\gamma-\beta) G-G b-\beta T_{g 0} b\right]}{\beta b}=F \\
C_{1} M_{1}+C_{2} M_{2}=F
\end{gathered}
$$


where

$$
\begin{gathered}
M_{1}=\left[\beta-\gamma-r_{1}\right] e^{r_{1} L_{\max }} \\
M_{2}=\left[\beta-\gamma-r_{2}\right] e^{r_{2} L_{\max }} \\
E=\frac{G b-\gamma G+\beta T_{g 0} b}{\gamma \beta b}-\frac{1}{\gamma} T_{a 0} \\
F=T_{\max }-G L_{\max }+\frac{\left[(\gamma-\beta) G-G b-\beta T_{g 0} b\right]}{\beta b}
\end{gathered}
$$

Using simultaneous Equations (A48) and (A49), this yields can get the following:

$$
\begin{gathered}
C_{1}+C_{2}=E \\
C_{1} M_{1}+C_{2} M_{2}=F \\
C_{1}=\frac{F-E M_{2}}{M_{1}-M_{2}} \\
C_{2}=\frac{F-E M_{1}}{M_{2}-M_{1}}
\end{gathered}
$$

Finally, substituting $C_{1}, C_{2}$ for Equations (A36) and (A37), where the analytical solution is shown as follows:

$$
\begin{aligned}
T_{a}= & -\frac{F-E M_{2}}{M_{1}-M_{2}} \gamma e^{r_{1} L}-\frac{F-E M_{1}}{M_{2}-M_{1}} \gamma e^{r_{2} L}+\frac{\beta G b}{\gamma b-(\gamma-\beta) b} L \\
& +\frac{\beta G b^{2}-\gamma \beta G b-(\gamma-\beta) \beta T_{8} b^{2}+\gamma \beta T_{80} b^{2}}{[\gamma b-(\gamma-\beta) b]^{2}} \\
T_{t}= & \frac{F-E M_{2}}{M_{1}-M_{2}}\left[\beta-\gamma-r_{1}\right] e^{r_{1} L}+\frac{F-E M_{1}}{M_{2}-M_{1}}\left[\beta-\gamma-r_{2}\right] e^{r_{2} L}+\frac{\beta G b}{\gamma b-(\gamma-\beta) b} L \\
& -\frac{\left[(\gamma-\beta) \beta G-\beta G b-\gamma \beta T_{80} b+(\gamma-\beta) \beta T_{80} b\right] b}{[\gamma b-(\gamma-\beta) b]^{2}}
\end{aligned}
$$

\section{References}

1. Clegg, J.D.; Bucaram, S.M.; Hein, N.W., Jr. Recommendation and Comparisons for Selecting Artificial-Lift Methods. J. Pet. Technol. 1993, 45. [CrossRef]

2. Fleyfel, F.; Meng, W.; Hernandez, O. Production of Waxy Low Temperature Wells with Hot Gas Lift. In Proceedings of the SPE Annual Technical Conference and Exhibition, Houston, TX, USA, 26-29 September 2004; pp. 26-29. [CrossRef]

3. Aliyeva, F.; Novruzaliyev, B. Gas Lift-Fast and Furious. In Proceedings of the SPE Annual Caspian Technical Conference \& Exhibition, Baku, Azerbaijan, 4-6 November 2015; pp. 4-6. [CrossRef]

4. Guo, B.; Duan, S.; Ghalambor, A. A Simple Model for Predicting Heat Loss and Temperature Profiles in Insulated Pipelines. Soc. Pet. Eng. 2006, 21. [CrossRef]

5. Muradov, K.M.; Davies, D.R. Novel Analytical Methods of Temperature Interpretation in Horizontal Wells. Soc. Pet. Eng. 2011, 16, 637-647. [CrossRef]

6. Brown, K.E. The Technology of Artificial Lift Methods; U.S. Department of Energy, Office of Scientific and Technical Information: Oak Ridge, TN, USA, 1984; Volume 4.

7. Poettmann, F.H.; Carpenter, P.G. The Multiphase Flow of Gas, Oil, and Water through Vertical Flow Strings with Application to the Design of Gas-Lift Installations; American Petroleum Institute: New York, NY, USA, 1952.

8. Bertuzzi, A.F.; Welchon, J.K.; Poettmann, F.H. Description and Analysis of an Efficient Continuous-Flow Gas-Lift Installation. J. Pet. Technol. 1953, 5, 271-278. [CrossRef]

9. Hasan, A.R.; Kabir, C.S. Wellbore Heat-Transfer Modeling and Applications. J. Pet. Sci. Eng. 2012, 86, 127-136. [CrossRef]

10. Gilbertson, E.; Hover, F.; Freeman, B. A Thermally Actuated Gas-lift Safety Valve. SPE Prod. Oper. 2013, 28, 77-84. [CrossRef]

11. Kirkpatric, C.V. Advanced in Gas Lift Technology; American Petroleum Institute: New York, NY, USA, 1959.

12. Ramey, H.J., Jr. Wellbore Heat Transmission. J. Pet. Technol. 1962, 14, 427-435. [CrossRef]

13. Shiu, K.C.; Beggs, H.D. Predicting Temperatures in Flowing Oil Wells. J. Energy Res. Technol. 1980, 102, 2-11. [CrossRef]

14. Hasan, A.R. A Mechanistic Model for Computing Fluid Temperature Profiles in Gas-Lift Wells. Soc. Pet. Eng. 1996, 11, 179-185. [CrossRef] 
15. Hasan, A.R.; Kabir, C.S.; Lin, D. Analytic Wellbore Temperature Model for Transient Gas-Well Testing. Soc. Pet. Eng. 2005, 8. [CrossRef]

16. Sagar, R.K.; Doty, D.R.; Schmidt, Z. Predicting Temperature Pro-files in a Flowing Well. SPE Prod. Eng. 1991, 6, 441-448. [CrossRef]

17. Tartakovsky, A.M.; Ferris, K.F.; Meakin, P. Lagrangian Particle Model for Multiphase Flows. Comput. Phys. Commun. 2009, 180, 1874-1881. [CrossRef]

18. Farrokhpanah, A.; Bussmann, M.; Mostaghimi, J. New Smoothed Particle Hydrodynamics (SPH) Formulation for Modeling Heat Conduction with Solidification and Melting. Numer. Heat Transf. Part B Fundam. 2017, 71, 299-312. [CrossRef]

19. Zeng, F.; Zhao, G.; Zhu, L. Detecting $\mathrm{CO}_{2}$ leakage in Vertical Wellbore through Temperature Logging. Fuel 2012, 94, 374-385. [CrossRef]

20. Alves, I.N.; Alhanati, F.J.S.; Shoham, O. A Unified Model for Predicting Flowing Temperature Distribution in Wellbores and Pipelines. Soc. Pet. Eng. 1992, 7, 363-367. [CrossRef]

21. Yu, Y.; Lin, T.; Xie, H.; Guan, Y.; Li, K. Prediction of Wellbore Temperature Profiles During Heavy Oil Production Assisted with Light Oil Lift. Soc. Pet. Eng. 2009. [CrossRef]

22. Lindeberg, E. Modelling Pressure and Temperature Profile in a $\mathrm{CO}_{2}$ Injection well. Energy Procedia 2011, 4, 3935-3941. [CrossRef]

23. Hamedi, H.; Rashidi, F.; Khamehchi, E. Numerical Prediction of Temperature Profile During Gas Lifting. Pet. Sci. Technol. 2011, 29, 1305-1316. [CrossRef]

24. Kabir, C.S.; Izgec, B.; Hasan, A.R.; Wang, X. Computing Flow Profiles and Total Flow Rate with Temperature Surveys in Gas Wells. J. Nat. Gas Sci. Eng. 2012, 4, 1-7. [CrossRef]

25. Duan, J.; Wang, W.; Deng, D.; Zhang, Y.; Liu, H.; Gong, J. Predicting Temperature Distribution in the Waxy Oil-Gas Pipe Flow. J. Pet. Sci. Eng. 2013, 101, 28-34. [CrossRef]

26. Cheng, W.L.; Nian, Y.L.; Li, T.T.; Wang, C.L. A Novel Method for Predicting Spatial Distribution of Thermal Properties and Oil Saturation of Steam Injection Well from Temperature Logs. Energy 2014, 66, 898-906. [CrossRef]

27. Han, G.; Zhang, H.; Ling, K.; Wu, D.; Zhang, Z. A Transient Two-Phase Fluid- and Heat-Flow Model for Gas-Lift-Assisted Waxy-Crude Wells with Periodical Electric Heating. Soc. Pet. Eng. 2014, 53. [CrossRef]

28. Hasan, A.R.; Kabir, C.S.; Wang, X. A Robust Steady-State Model for Flowing-Fluid Temperature in Complex Wells. Soc. Pet. Eng. 2009, 24, 269-276. [CrossRef]

29. Wei, L.; Qian, Y. New Prediction Model for Temperature Distribution in Gas Lift Annulus Hot Gas Injection Wellbore. Oil Gas Field Dev. 2014, 32, 41-44.

(C) 2018 by the authors. Licensee MDPI, Basel, Switzerland. This article is an open access article distributed under the terms and conditions of the Creative Commons Attribution (CC BY) license (http://creativecommons.org/licenses/by/4.0/). 